\title{
Lotófagos, Sirenas y otros seres: la construcción de la alteridad neutra en la épica griega
}

Loto Eaters, Syrens, and Other Beings: the Building of the Neutral Alterity in the Greek Epic

Bárbara Álvarez Rodríguez ${ }^{*}$

Universidad Internacional de La Rioja, España

barbaralvarezrodriguez@hotmail.com

(iD http://orcid.org/0000-0002-4645-9509

\section{Resumen:}

En el imaginario homérico la relación de los hombres con los «Otros» monstruosos se plantea como una suerte de lucha entre la bestialidad y la racionalidad. El peligro que acecha a Odiseo y sus compañeros en todos estos encuentros es la muerte, pero no se trata de una cualquiera, o de la "bella muerte" que aguarda al caído en la batalla, sino de un final ignominioso, puesto que significa el olvido. Frente a esto, los únicos recursos con los que cuentan los héroes son la ayuda de los dioses y el uso de la razón, manifestada a través de la astucia. En este artículo realizaré un análisis filosófico de algunos de los encuentros con lo monstruoso con el fin de intentar comprender mejor la relación de los humanos con la alteridad neutra o impersonal. El relato de viajes le sirve al poeta para recrear un mundo extremadamente alejado de los cánones humanos, en el que las experiencias de la vida cotidiana resultan insuficientes, las normas sociales habituales no se respetan, y los peligros resultan mucho más difíciles de manejar, en un espacio fronterizo poblado de monstruos.

Palabras clave: Odisea, Alteridad neutra, Monstruosidad, Épica, Filosofía.

\section{ABSTRACT:}

In the Homeric thought the relationships among men and the monstrosity alterity is seen as a king of fight between beastliness and rationality. The dangers waiting for Odysseus and his companions in all these encounters is the death, not a beautiful death thought, but an ignominious end, since it means the oblivion. The only sources for the heroes to fight against it is the god's help and the use of their rationality or their cunning. The main aim of this paper is to draw a philosophical analysis of some of the Odysseus' encounters with the monstrosity in order to get a better understanding the relationship among humans and the neutral alterity. The Sirens, the Cyclopes or the Laestrigones belong to the radical otherness, the totally Other. Through the story of travel, the poet draws a dystopian world, completely away from human standards, where social norms are not respected, and the experiences of daily life are not enough to deal with the dangers that this border area presents.

KEYWORDS: Odyssey, Neutral alterity, Monstrosity, Epic, Philosophy.

\section{INTRODUCCIÓN 1}

Como es bien sabido, la Odisea cuenta la historia de un largo viaje lleno de aventuras que lleva al héroe hacia tierras lejanas y desconocidas. Estos terrenos son imaginados y descritos por la tradición épica como parajes peligrosos y atestados de amenazas. En ocasiones esos peligros toman forma de criaturas monstruosas a los cuales Odiseo y sus compañeros tienen que hacer frente antes de volver a su casa, Ítaca. Cuando el poema fue compuesto, el viaje por mar era una actividad que muy pocas personas podían hacer (a pesar de que la navegación ya existía, era una actividad sumamente peligrosa y extraordinaria). Esto explicaría que el motivo del viaje de Odiseo a través de los mares llegase a tener un particular atractivo como tópico literario, que permitiría al narrador dar forma a las más diversas fantasías. Fantasías que también reflejaban los propios miedos que sacudían a la audiencia.

Los encuentros de Odiseo con los diferentes seres monstruosos son contados por él mismo durante su estancia en la tierra de los feacios en el canto 9 de la Odisea (Od. 9.166-12.450), donde el héroe se aloja como huésped del rey Alcínoo. Allí, Odiseo se convierte en narrador de su propia historia y nadie duda de la 
veracidad de sus palabras, precisamente porque él ha viajado y ha conocido de primera mano aquellos lugares tan remotos que están lejos de las experiencias cotidianas del común de los mortales. ${ }^{2}$ Es en estos lugares donde el poeta sitúa los encuentros con lo monstruoso.

En el poema, las criaturas que voy a analizar en este artículo son definidas como el contra-modelo de las normas, valores y moral humanas. En general, estos seres son presentados con una apariencia humana o semihumana pero, al mismo tiempo, tienen características distorsionadas en su apariencia, su comportamiento o en sus relaciones sociales y esta mezcla de características que recuerdan a lo humano pero, a su vez, difieren de ello es, precisamente, lo que más perturba y provoca temor, acercando a estos seres al terreno de la alteridad neutra o impersonal, ${ }^{3}$ al mundo distópico, no deseable. Esta categoría engloba la alteridad no humana (ni biológica ni políticamente): será «lo Otro». Aquí entrarían alteridades como lo Monstruoso o la Muerte.

Concretando un poco más, esta categoría de la alteridad se puede subdividir en dos: lo «Otro neutro natural $\gg$ y lo «Otro neutro cultural $\gg$. La alteridad natural se corresponde con los animales o con la propia Naturaleza: aquí entran un tipo de «Otros» neutros, asexuados y (al menos la Naturaleza) fuera del tiempo y espacio humanos. En la alteridad cultural, a su vez, se engloban todos los «Otros» impersonalizados; son los «Otros» construidos por los seres humanos, que les niegan la personalidad. Aquí entra lo monstruoso y es la que será objeto de este artículo. Son «Otros» imaginarios, constructos humanos con carga negativa o positiva. Este «Otro» se encuentra desespacializado o, de no estarlo, aparece en un espacio con unas características peculiares. En el caso del universo homérico, como veremos, encontramos a estos «Otros» culturales siempre viviendo en los límites, en una geografía de confines, que constituye el tópos donde habita lo monstruoso.

\section{CÍCLOPES Y LESTRIGONES: SALVAJE VERSUS CIVILIZACIÓN}

El episodio que, desde mi punto de vista, mejor muestra las características de esa alteridad transformada en monstruo es el encuentro de Odiseo con el Cíclope Polifemo. Los cíclopes son descritos como criaturas salvajes, lo opuesto a los hombres civilizados que habitan las comunidades homéricas. Las palabras que pone el poeta en boca de su héroe expresan magníficamente la total extrañeza que le provoca el primer encuentro con la forma de vida del cíclope, que pronto dará lugar al temor. Narra Odiseo:

Pero cuando ya llegamos a la tierra, que estaba cerca, / vimos allí en un extremo una caverna próxima al mar / elevada, tapada por laureles. Y allí pasaban la noche muchos rebaños, ovejas y cabras. Alrededor había construido un recinto / elevado, con piedras hincadas en la tierra / y altísimos pinos y encinas de frondosas copas. / Y allí vivía un hombre monstruoso

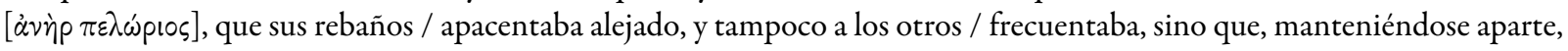

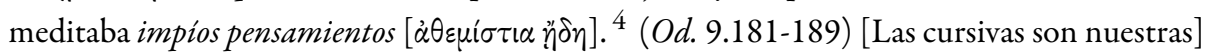

Como acertadamente indica Mastromarco (1998, p. 10), Homero se preocupa desde el principio de mostrarnos en Polifemo a un ser ambiguo, que tiene algo de "hombre" ( $\alpha \nu \eta ́ p)$, pero que no es totalmente humano, como pone de manifiesto el adjetivo $\pi \varepsilon \lambda \omega ́$ pıos. Además, en dos ocasiones a lo largo del canto se

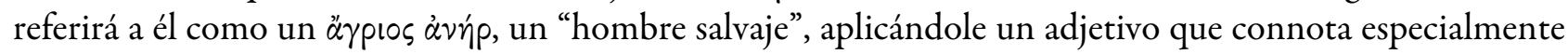
el carácter de los animales no domesticados, y que cuando se refiere a la especie humana es claramente peyorativo, describiendo bien acciones que rompen el orden social, bien a hombres que no respetan dicho

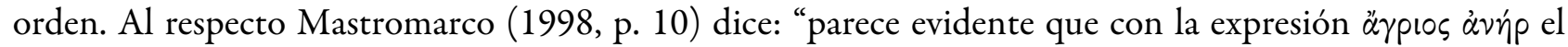
poeta se proponía presentar al monstruoso Polifemo como un ser 'ambiguo'. Junto a ciertas características que lo hacen similar a las bestias, el cíclope presenta elementos peculiares del hombre, empezando por el uso de la palabra".

Analizaré en detalle cómo Homero dibuja a este grupo de criaturas, en especial a Polifemo. Para comenzar, está el aspecto físico. Cuando por primera vez Odiseo escucha y ve al cíclope, el terror se apodera de su cuerpo "temiendo su terrible voz y al propio monstruo" (Od.9.257). Odiseo aún ignora el talante de Polifemo, pero 
su voz y su apariencia le producen temor, pues esta presenta dos rasgos que lo hacen ajeno a los hombres, caracterizándolo como un monstruo. Por un lado, posee un tamaño enorme, imposible en la escala humana, que lo dota, al mismo tiempo, de una fuerza descomunal. Según la descripción que se ha dado en un punto anterior del relato, "causaba asombro el monstruo, / y no se asemejaba a un hombre comedor de pan, sino a un promontorio boscoso / de los elevados montes, que se muestra aislado por encima de los demás" ( $O d$. 9.190-192). Como puede apreciarse, la comparación con la cima de una montaña incide, además, en la "cosificación" del cíclope. Pero es que, aparte de eso, al igual que todos los de su especie, Polifemo tiene un solo ojo (Od. 1.69, 9.332 y 383), situado, anómalamente, en medio de la cara, ${ }^{5}$ esto es, en una posición distinta a la que ocupan los ojos en los seres humanos. ${ }^{6}$

A pesar de que en la Odisea no se especifica cómo estaba constituido el rostro del cíclope, todo parece indicar que el ojo ocupaba un lugar central, tal como lo ha presentado siempre la tradición, encontrándose la primera indicación explícita al respecto en la Teogonía de Hesíodo (141-146). Así dice el poeta: "Éstos en lo demás eran semejantes a los dioses (pero en medio de su frente había un solo ojo). Cíclopes era su nombre por eponimia, ya que, efectivamente, un solo ojo completamente redondo se hallaba en su frente" (trad. de Pérez Jiménez y Martínez Díaz, 1978, p. 44). Este rasgo anómalo es el que precisamente inspira el nombre

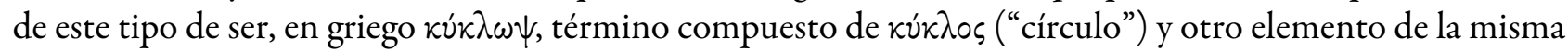
raíz de őభı (“vista, mirada, ojo”). Es interesante destacar que en el imaginario homérico la belleza física se vincula con el bien o lo bueno, mientras que la fealdad se relaciona con lo inferior o malo. Gracias a nuestra tradición cultural, especialmente, al cine y a la literatura, hoy parece fácil imaginarse villanos con los rostros más atractivos del mundo, pero para el público al que iban destinados los poemas homéricos un físico como el de los cíclopes necesariamente denotaba que quien lo poseía era un ser brutal tanto por fuera como por dentro. Así, el tradicional refrán "Monstruo de cuerpo, monstruo de alma" ("Monstrum in fronte, monstrum in animo") queda ya asentado en la iconografía ciclópica de los poemas. Como acertadamente sostiene Belén Altuna (2010, p. 171), "Lo importante es que tiene que haber una equiparación entre el interior y el exterior, y que, sobre todo el mal, la intención perversa, debe aparecer en forma de estigma, fealdad o monstruosidad en la superficie visible". En la figura del cíclope Polifemo, como tendremos ocasión de ver a continuación, la fealdad física es, efectivamente, paralela a la fealdad moral.

Otro signo de la alteridad de los cíclopes es su hábitat. Los cíclopes carecen no solo de poblados, sino incluso de casas, ya que viven en cavernas (Od.9.113-114). Las cavernas, en el imaginario griego, representan los estadios de civilización más atrasados, ya que, como dice Buxton (2000, pp. 107-109), fue necesario que Prometeo diera el fuego a los hombres, y con ello la cultura, para que estos dejaran de vivir en la profundidad de las cuevas oscuras. En la mitología griega estos refugios naturales dan cobijo a todo tipo de seres marginales. Por ejemplo, las Harpías vivían en cuevas. En la Odisea también la ninfa Calipso tiene una caverna por morada (Od. 5.55-57). Los cíclopes se encuentran también entre ellos. La que sirve de morada a Polifemo está cercana a la playa, en un lugar elevado, y en su parte superior crecen laureles. Está protegida alrededor por un alto cercado hecho a base de árboles enteros y grandes piedras hincadas en la tierra (Od.9.180-184). Además, Polifemo comparte su cueva con sus rebaños, vive entre ellos como si de un animal más se tratara. Es muy significativo en este aspecto que en el canto 9 de la Odisea (329-330) se dice que el héroe esconde el palo de olivo con el que cegará al cíclope bajo el estiércol que había esparcido, en gran cantidad, por la caverna, en el mismo suelo donde Polifemo se echa a dormir a diario. Este dato parece apuntar implícitamente a que Polifemo es un ser maloliente (Mastromarco, 1998, p. 14). Ahora bien, en el imaginario griego el "buen olor", la $\varepsilon \dot{\omega} \omega \delta i ́ \alpha$, representa una característica peculiar de los dioses y de los héroes, es un símbolo de su condición suprahumana. Por otro lado, a pesar de que los cíclopes conocen el fuego, ya que al caer la noche Odiseo y sus compañeros contemplan desde la distancia sus fogatas (Od.9.166-169), no lo utilizan, como las comunidades humanas, aprovechando su capacidad transformadora, para fabricar objetos que, a su vez, les permitan modificar su hábitat, sino que todo parece indicar que se sirven de él solo como fuente de luz y calor. 
Uno de los aspectos culturales que más aleja a los cíclopes de los hombres y que, por el contrario, los acerca a ese mundo de lo monstruoso, es el que tiene que ver con la alimentación. Ya mencioné cómo Homero dice que Polifemo no se parecía a un hombre "comedor de pan" ( cíclopes no son agricultores ("ni plantan fruto con su mano ni labran la tierra", Od.9.108), lo cual marca una clara diferencia con las comunidades humanas que aparecen en los poemas homéricos, donde los campos

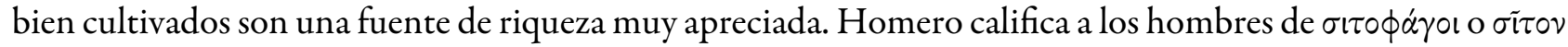

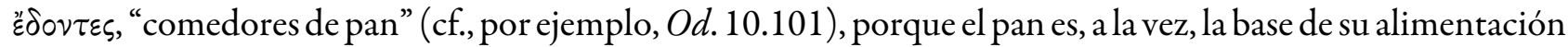
y un símbolo de la cultura humana que él conoce. Para hacer pan se requiere no solo disponer de tierras de labor apropiadas y saber cómo cultivar el cereal, sino también conocer toda una serie de técnicas, puesto que el grano ha de ser luego trillado, molido, cernido, amasado y, finalmente, cocinado en un horno. Por ello, el pan es un signo de civilización y de sociabilidad, implica que quien lo consume posee un asentamiento estable y forma parte de una comunidad que trabaja en grupo. En clarísimo contraste con esto, el cíclope no cocina su comida, sino que la come cruda y, además, no duda en consumir de ese modo incluso la carne humana (Od. 9.288-298), un hecho que Homero presenta como el mayor de los horrores, la violación más radical de las normas básicas de la convivencia. La narración del episodio en el que Polifemo devora a dos compañeros de Odiseo muestra una crudeza extrema. Cuenta Odiseo:

Él, por su parte, dio un salto y echó sobre mis compañeros sus manos, / agarró a dos y como si fuesen unos cachorros los golpeó contra el suelo / y sus sesos fluyeron por el pavimento y mojaron la tierra. / Y cortándolos miembro a miembro se preparaba la cena. / Y comía como un león montaraz, sin dejar nada, / entrañas y carne y huesos llenos de tuétano. (Od.9.288-293)

La antropofagia, unida al hecho de comer la carne cruda, convierte al cíclope en la antítesis de los valores humanos que conoce y acepta Homero, es un rasgo de alteridad radical, que lo iguala a las fieras salvajes. Después de comer a algunos de los compañeros de Odiseo, Homero, para resaltar aún más la inhumanidad del acto, nos cuenta que el cíclope se echa a dormir; aquí se ve que en nada agita la conciencia de Polifemo el haber cometido tal acto atroz a los ojos de un humano. Longo (1975, p. 63 y ss.) resume perfectamente la crudeza de este pasaje:

La salvaje comida del feroz cíclope, ya de por sí abominable por antropófaga, es también anormal, no cultural; propia de fieras, en suma, por el modo en que tiene lugar, totalmente al margen de las convenciones de la vida civil normal. Polifemo se limita a descuartizar toscamente a sus víctimas y las devora por entero, sin dejar nada. Es semejante, por tanto, al león, que no conoce distinción entre partes comestibles y no comestibles. Se coloca a un nivel un poco más «cultural» que esta fiera solo en la medida en que realiza sobre sus víctimas un somero descuartizamiento, mientras que el león, se dice, devora a sus víctimas enteras sin descuartizarlas [...] no distingue entre las partes de sus víctimas, se lo come todo en confusión: carne, vísceras, huesos. Aún más, pese a conocer el uso del fuego, a los compañeros de Odiseo los devora crudos; lo mismo que es antropófago, también es comedor de carne cruda, como lo son en Homero los leones, chacales, perros, buitres. ${ }^{7}$

Los cíclopes, por otro lado, son seres sin ley (Od. 9.107), que no tienen derecho consuetudinario, a diferencia de los aqueos y de otros pueblos presentes en los poemas (troyanos, feacios, etc.), con todo lo que ello implica de falta de garantía social ante los posibles desmanes que puedan cometer los unos contra los otros. Dice el poeta que "entre ellos no hay asambleas que decidan en consejo, ni leyes, / sino que lo que es ellos habitan las cumbres de los elevados montes en / cavernas profundas, y cada uno administra justicia / a sus hijos y esposas, y no se ocupan los unos de los otros" (Od. 9.112-115). Cuando las gentes se ven obligadas a compartir un mismo espacio geográfico, son necesarias unas leyes de convivencia, que se rijan por unos presupuestos aceptados por la mayoría o por un determinado grupo (como sería el caso de las comunidades de los poemas, que están dirigidas por los nobles guerreros). Estas normas han de basarse tanto en el consenso (asambleas) como en la justicia para con el «Otro» (en el caso homérico, fundamentalmente, el «Otro» de la misma comunidad, el vecino). Pero los cíclopes carecen abiertamente de todo ello: a los unos no les importan los otros y, todo lo más, cada unidad familiar tiene sus propias reglas, marcadas por la mera voluntad y capricho del padre de familia, que tiene potestad absoluta sobre su mujer y sus hijos, y 
marca y hace cumplir lo que le parece bien. No parece importar, en cambio, que las decisiones de alguien puedan afectar negativamente a los demás. Esto significa que cada uno actuará conforme a su libre arbitrio sin atender a si las consecuencias de su acción afectarán a la colectividad en la que se vive. Sí es cierto, sin embargo, que en el momento más crítico de Polifemo, cuando Odiseo le clava la estaca en su único ojo, el cíclope pide ayuda a gritos a los demás, que acuden cerca de su cueva (Od.9.398-402). Son interesantes, a este respecto, las preguntas que le hacen los demás cíclopes sobre la naturaleza de sus gritos:

¿Qué cosa tan grande sufres, Polifemo, para gritar de esa manera / en la noche inmortal y dejarnos sin sueño? ¿ ¿Es que alguno de los mortales se lleva tus rebaños contra tu voluntad? / ¿O te está matando alguien con engaño o por la fuerza? (Od. 9.403-406)

Los motivos que los demás cíclopes piensan que pueden originar el sufrimiento de Polifemo están relacionados con un ataque externo humano, es decir, parece que nadie de la comunidad se plantea que otro cíclope haya podido ser el incitador de la desgracia de uno de los suyos, lo que es indicativo de un estatuto en el que cada uno procura vivir y dejar vivir sin intervenir para mal, lo mismo que tampoco para bien, en la vida de los demás.

Además de carecer de leyes, los cíclopes tampoco se rigen por las normas divinas que en la sociedad humana que Homero conoce contribuyen a suplir en parte la ausencia de un derecho normalizado y se erigen en reguladoras de la ética. Los cíclopes carecen de piedad hacia los dioses y así, por ejemplo, no cumplen el deber de hospitalidad (Od.9.273-278). Es más, el episodio de antropofagia de Polifemo anteriormente mencionado se presenta como doblemente monstruoso, pues se da en contra de los deberes de xenía.

La acción de acoger a un extranjero como huésped en la casa propia constituye una institución social enormemente arraigada entre los nobles homéricos, que se conoce como "deber de xenía" ( $\xi \varepsilon v i ́ \alpha)$ o "deber de hospitalidad". Cuando un extranjero (un noble) llegaba a una casa o a una corte de un país extraño, lo primero que hacían sus anfitriones era ofrecerle comida, bebida y lavado, para que el extraño se pudiera recuperar del cansancio del viaje. Luego, se le hacían las típicas preguntas sobre su procedencia, qué le había llevado a viajar hasta allí, etc. Después, se le ofrecía alojamiento por el tiempo que fuera necesario. Finalmente, antes de su partida, el anfitrión le ofrecía al huésped algunos presentes para que se los llevara a su casa, como símbolo de su hospitalidad. Gracias al deber de xenía, el viajero gozaba de una garantía, de un respaldo, cuando salía de su comunidad, ya que sabía que, por regla general, en cualquier sitio al que fuera iba a encontrar una ayuda en el camino, tanto de cara a su alojamiento como a su manutención. El deber de xenía era recíproco, ${ }^{8}$ de manera que quien fuera acogido como huésped en casa de alguien, debía en el futuro recibir a esa misma persona en su hogar (o a sus descendientes, pues el estatus de "huésped de" era hereditario), y corresponder con nuevos regalos. Además, los vinculados por una relación de hospitalidad no podían mantener en el futuro relaciones hostiles entre sí, y estaban obligados a prestarse ayuda mutuamente si la ocasión así lo requería. Pues bien, merece la pena subrayar que la primera intención de Odiseo al encontrarse con Polifemo es establecer con él el mismo tipo de relación que era costumbre en la época, la relación de hospitalidad entre huéspedes. Así le dice: "Nosotros, por nuestra parte, venidos aquí a tus rodillas / nos llegamos, por si nos otorgases un regalo de hospitalidad o por si también de otra manera / nos dieses el obsequio que es norma entre huéspedes" ( $O d$. 9.266-268), a lo que el cíclope responde: "Eres un necio, extranjero, o has venido de lejos, / tú que me instas a que tema o respete a los dioses. / No se cuidan los cíclopes de Zeus portador de la égida, / ni de los dioses bienaventurados, pues somos sin duda más fuertes; / yo por evitar el enojo de Zeus no te perdonaría / ni a ti ni a tus compañeros, si mi ánimo no me incitara a ello" (Od.9.273-278). Y para remarcar aún más esta forma de barbarie, el cíclope ofrece como don de hospedaje al huésped comérselo el último: “A Nadie 9 [refiriéndose a Odiseo] yo me comeré el último entre sus compañeros, / y a los otros, primero; éste será para ti mi regalo de hospitalidad" (Od.9.369-370). Con esta terrible respuesta, al héroe no le queda otra salida que echar mano de su racionalidad, de su astucia, capacidad tan típicamente humana, para salir airoso del encuentro: "Entonces me puse a deliberar cómo saldrían mejor las cosas / (...) Y me puse a entretejer toda clase de engaños y planes, / 
ya que se trataba de mi propia vida" (Od. 9.420 y 422-423). En los demás aspectos, Odiseo sabe que está en inferioridad de condiciones ante el monstruo: es más pequeño, menos fuerte y se encuentra alejado de la seguridad que le otorga su propia comunidad. Al final, la astucia vence a la fuerza bruta; Odiseo engaña al cíclope (se hace llamar "Nadie", lo que le salvará de que los otros cíclopes atiendan a los gritos de socorro de Polifemo), lo emborracha con vino puro, lo ciega y consigue salir de la cueva de Polifemo camuflado bajo uno de sus carneros.

Aparte de la insociabilidad hacia los seres humanos que caracteriza al grupo de los cíclopes en general, Polifemo aparece representado como la insociabilidad en estado puro, pues ni siquiera tiene familia (esposa e hijos) ni contacto con los demás miembros de su grupo. En clara contraposición con ello está el modo en que Polifemo se relaciona con sus rebaños y, en especial, con el más grande de sus carneros, al que llega a llamar

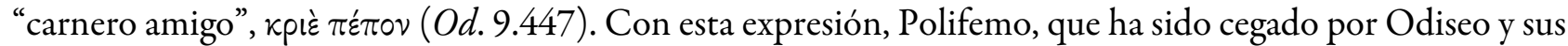
compañeros, está dirigiéndose al carnero como si fuera un noble guerrero al que pidiera auxilio, ya que, como bien indica Mastromarco (1998, p. 19):

En la Odisea, $\pi \dot{\varepsilon} \pi \omega \nu$ solo aparece como adjetivo en este pasaje, mientras que en la Ilíada aparece en cuatro episodios, en contextos en los que un guerrero herido (como herido está el cíclope) o en dificultades (porque acaba de morir un compañero) pide ayuda a otro guerrero dirigiéndose al otro con el vocativo $\pi \dot{\pi} \pi \circ{ }^{10}$

Aparte de esto, Polifemo le atribuye al animal sentimientos propios de los humanos; por ejemplo, dice que, al atardecer, siente nostalgia de retornar a su establo (Od.9.451-452), y relaciona el retraso con el que el carnero sale de la caverna con un sentimiento de solidaridad del animal, de empatía con la desgracia de su dueño, que ha sido cegado por Odiseo $(O d .9 .452-453)$. Vemos, por tanto, que los sentimientos que Polifemo no es capaz de sentir hacia los hombres los tiene, en cambio, hacia los animales que están a su cargo.

El episodio de Polifemo no es el único en el que el héroe y sus compañeros se ven obligados a tener un encuentro en estas tierras distópicas. De hecho, su viaje de vuelta está plagado de este tipo de situaciones cuya constante parece ser el distanciamiento, tanto geográfico como cultural, de los pasajes y costumbres humanas. Otro ejemplo de ello aparece en el canto 10 de la Odisea con la tribu de los Lestrigones, un grupo de gigantes antropófagos que vive en una tierra remota en donde "los caminos del día y de la noche están cercanos" (Od. 10.86). Llama la atención, ya desde el principio, un rasgo anómalo de su tierra, puesto que "allí no se veían labores ni de bueyes ni de hombres" ( $O d$. 10.98); es decir, que, como los cíclopes, los lestrigones no cultivaban la tierra, lo cual en el imaginario homérico es un claro indicio de falta de civilización. A diferencia de los cíclopes, los lestrigones sí tienen poblados, además de ciertas infraestructuras como, por ejemplo, caminos por los que pueden pasar carros que llevan leña. El dotar a este pueblo de algunos rasgos propios de las sociedades humanas también servía para permitir al poeta hacer más verosímil su historia, es un mecanismo del que se sirve Homero para añadir credibilidad al relato. Ahora bien, en la descripción de las características de los lestrigones encontramos así mismo elementos propios de la alteridad total. Físicamente, los aparta de los estándares humanos, al igual que ocurría con los cíclopes, su tamaño desmesurado: "su talla es gigante, mayor que la humana" (Od.10.120), dice el poeta. Desde el punto de vista cultural, aparte de la carencia de agricultura, el rasgo que más los aleja de lo humano, provocando repulsión y terror, es, nuevamente, la antropofagia; su rey, Antifates, no duda en servirse uno de los compañeros de Odiseo como almuerzo (Od. 10.114-116).

\section{LA MUERTE VERDADERA: EL OLVIDO}

Por otra parte, conviene apuntar que, en los poemas, una de las peores cosas que le puede suceder a un héroe es la falta de gloria que ocurriría si es olvidado y, por ello, desconocido para las generaciones venideras. En el imaginario homérico el reconocimiento por parte de los contemporáneos y el recuerdo por parte de los sucesores es muy importante, al punto de que los héroes están realmente preocupados por saber 
si sus hazañas se mantendrán vivas en la memoria de sus descendientes, lo que les garantizaría cierto tipo de inmortalidad, ya que el olvido, para ellos, es lo mismo que la muerte. Hay un episodio que incide en ese temor al olvido, el de los Lotófagos. En esta ocasión la distopía se construye en torno a una tierra en la que olvido y muerte van de la mano, a través del encuentro con un pueblo que no trama la muerte física de quienes llegan a su tierra (Od. 9.92), al contrario, los acoge sin hostilidad, pero que acarrea unas consecuencias igualmente terribles para los héroes. Hay que decir que los lotófagos no poseen características físicas distintas a las de las personas corrientes, pero sí comparten con la alteridad de cíclopes y lestrigones una geografía de confines y, sobre todo, el alejamiento de las costumbres y hábitos humanos. El peligro al que se enfrentan Odiseo y sus compañeros en la tierra de los lotófagos está directamente relacionado con el fruto con el que estos se sustentan y que ofrecen inmediatamente a todos los que llegan a su país. Ahora bien, las consecuencias de la ingesta del loto son tan inesperadas como tremendas, narra el poeta: "Cualquiera de ellos que comiera el fruto dulce como la miel del loto / ya no deseaba dar noticias de nuevo, ni regresar; / al contrario, querían permanecer allí mismo entre los lotófagos / arrancando loto, y olvidarse del regreso" (Od. 9.94-97). Comer el loto, por tanto, significa olvidar quién es uno mismo, de dónde viene, quiénes son sus amigos y su familia, es decir, las propias señas de identidad, el conocimiento o reconocimiento de su propia persona. La droga que contiene el loto provoca que la persona adicta ya no sea capaz de hacer otra cosa que seguir en el mismo sitio consumiéndolo. Quiere ser un lotófago, y no lo que era antes. Odiseo se da cuenta del gravísimo peligro que ello constituye, se lleva a la fuerza a los compañeros que ya han probado la flor (los tienen que atar en la nave para que no huyan), y se va del país a toda prisa, antes de que alguno de los otros sufra el mismo proceso de alienación (Od. 9.99).

Otro episodio interesante es el de las Sirenas $(O d .12 .166-201)$. Homero no da ninguna descripción física de ellas, solo dice que son dos y que pertenecen al género femenino. Así que en el poema no hay, al menos de forma explícita, la concepción de las Sirenas como seres híbridos (mitad pájaro, mitad mujer). Como otros seres monstruosos, las Sirenas viven en un espacio anómalo, en esta ocasión en una pradera de una isla rodeada por los restos putrefactos de los viajeros que han matado. El miedo a este Otro corpóreo aparece, nuevamente, vinculado al miedo a una muerte en el olvido más absoluto. Así dice Homero: "Quien sin saberlo se acerca y escucha la voz / de las Sirenas, a ese ya nunca su esposa y sus tiernos hijos / lo tendrán a su lado, tras regresar él a casa, ni se alegrarán, / sino que las Sirenas lo hechizan con su melodioso canto" (Od. 12.41-44). Es decir, quien se deja seducir por su canto morirá irremediablemente y, además, quedará insepulto. En el imaginario homérico para alcanzar la supervivencia del nombre propio es importante que el recuerdo se apoye en un símbolo físico, visible, bajo la forma de monumento funerario que sirva como mecanismo de evocación al recuerdo. Para el héroe homérico ese símbolo equivaldría a no ser olvidado, a mantener el recuerdo vivo en la memoria de las generaciones venideras. En una sociedad preliteraria como la homérica, es decir, sin escritura, este tipo de símbolos ayudaban a conservar la memoria colectiva del pasado. El encanto del canto de las Sirenas no es, como se podría pensar en un principio, la belleza de su voz sino el contenido de su canción: las Sirenas seducen al viajero con la promesa del conocimiento, ya que se jactan de conocer todo lo que está pasando o ha pasado sobre la tierra. Estas son las palabras que utilizan cuando tratan de seducir a Odiseo:

Vamos, famoso Odiseo, gran honra de los aqueos, / ven aquí y haz detener tu nave para que puedas oír nuestra voz. / Que nadie ha pasado de largo con su negra nave sin escuchar la dulce voz de nuestras bocas, / sino que ha regresado después de gozar con ella y saber más cosas. / Pues sabemos todo cuanto los argivos y los troyanos / trajinaron en la vasta Troya por voluntad de los dioses. / Sabemos cuanto sucede sobre la tierra fecunda. (Od. 12.184-190)

Las Sirenas se valen de la sed humana por el conocimiento, como la serpiente en el Jardín del Edén, pero en esta ocasión las consecuencias de escucharlas es el olvido de una muerte ignominiosa, sin sepultura, sin recuerdo.

El último episodio que trataré es el de Escila y Caribdis, que viven en medio del mar. Gracias a la descripción que da Homero de Escila y su morada sabemos por adelantado que, nuevamente, nos encontramos en el terreno de la alteridad más extrema. Vive en una cueva, donde mantiene oculta una mitad de su cuerpo, mostrando solo su parte superior, mientras espera a los viajeros, acechándolos, al tiempo que profiere unos 
horribles aullidos parecidos a los de un cachorro, "pero ella es un monstruo maligno", aclara el poeta (Od. 12.87): tiene doce patas deformes y seis horribles cabezas con las bocas abiertas que enseñan tres hileras de dientes $(O d$. 12.92). De cada nave de Odiseo que pasa se lleva seis hombres, uno con cada cabeza (Od. 12.246-247). Por su parte Caribdis no se describe por sus propias características físicas, sino a través de sus efectos: este monstruo ingiere las aguas y las vomita y las sorbe tres veces al día, provocando así una fuerte resaca $(O d .12 .106)$, devolviendo las naves, pero tragándose su contenido. La construcción de ambos monstruos va un paso más allá en la deshumanización de lo desconocido que produce los miedos, ya que ninguna de las criaturas posee característica humana, ni siquiera poseen una voz capaz de articular palabra inteligible. En cambio, solo poseen una ciega e incontrolable inclinación a matar y destruir todo lo que pase por su lado. Por ese motivo también Homero hace que Circe advierta a Odiseo antes de su encuentro con ellas de que en este caso cualquier tipo de reacción humana normal de defensa carece por completo de sentido y efectividad. No se puede tratar con estos monstruos como con los seres humanos, ni se los puede tampoco dominar por la fuerza, como inicialmente se plantea ingenuamente Odiseo, sino que la única actitud sensata es huir (Od. 12.120).

\section{ConCluSión}

Como hemos visto, a lo largo de su viaje de vuelta a casa Odiseo se encuentra con varios peligros, cuya última consecuencia es la muerte, a veces en una forma explícita y violenta, pero, precisamente, porque el héroe se da cuenta del peligro este puede luchar contra él. Pero otras amenazas son incluso más peligrosas, ya que el peligro es más sutil y los héroes no lo pueden reconocer y sucumben a él casi de forma voluntaria, debido al encanto del producto que las criaturas ofrecen, como un dulce fruto o la promesa del conocimiento.

Como ya adelanté, desde mi punto de vista, estos encuentros podrían ser entendidos como manifestaciones del miedo que lo desconocido provoca. ¿Y qué es lo desconocido? Lo que no puede ser aceptado como perteneciente a la identidad humana, lo Otro.

El poeta era el encargado de acumular esas narraciones mitológicas en donde se les daba forma a los miedos, externalizándolos, convirtiéndolos en esas criaturas, en esos monstruos que estaban siempre encallados en un lugar fijo, siempre dentro de una región concreta. Es importante mencionar que ninguno de los monstruos que vimos puede moverse del lugar en el que habita: ninguno de ellos, por ejemplo, puede ir en persecución de los viajeros con los que se encuentra, sino que se quedan esperando la llegada del siguiente. Como he mencionado al principio, el poeta utiliza el relato de viajes para construir un mundo extremadamente lejano e indeseable, completamente distinto de los estándares humanos, en el que las experiencias cotidianas son insuficientes, las normas consuetudinarias no son respetadas y los peligros son mucho más difíciles de manejar ya que están en un espacio fronterizo plagado de seres monstruosos.

Las claves ofrecidas por el poeta para darnos cuenta de que nos encontramos en el mundo distópico de la alteridad más radical son su localización en un lugar fronterizo, la lejanía de los valores, normas y hábitos civilizados y, en ocasiones, el aspecto externo de estas criaturas.

No parece entonces muy desacertado afirmar que entre los mayores miedos de los seres humanos está el miedo a lo desconocido, el miedo al Otro. Por ello, a lo largo de la historia de la humanidad, hemos sido testigos de un intento constante de personificar esos miedos, tratar de ponerles forma, cara. En definitiva, tratar de delimitarlos, de superarlos/dominarlos, transformando esos miedos en criaturas concretas, nombrables. La Odisea se presenta como una magnífica muestra de ello. El poeta construye esas criaturas monstruosas como perfectos representantes de lo Otro, con características físicas, sociales y morales completamente opuestas a lo humano-conocido. De hecho, en cierto sentido, los construye como el contramodelo de lo consensuado, de lo tradicional. Además, Homero sitúa a estos monstruos en un lugar geográfico fronterizo, localizados en los confines del mundo conocido para él y su audiencia. Todo ello podría entenderse como una especie de mecanismo por el cual las personas tratan de controlar a lo desconocido, o más bien, 
controlar su propio miedo a ello, reflejado en la construcción de un monstruoso y corpóreo Otro, obviamente hostil y amenazador pero que, por el simple hecho de estar localizado dentro de un cuerpo físico, el ser humano puede encarar.

Por tanto, se podría entender este tipo de relación con la alteridad neutra como una relación con nuestro otro yo, con nuestros miedos, nuestras inquietudes, nuestros temores, etc. Por otra parte, la alteridad que conlleva lo monstruoso podría verse como la negación de todo lo que implica la sociabilidad propia de los humanos; lo monstruoso es lo que se encuentra fuera de los límites de lo humano, fuera de nuestro control (al igual que la Muerte). Ello significa que jamás llegaremos a conocerlo, nunca lo asimilaremos; por eso mismo forma parte de la alteridad extrema, radical, y producirá pavor en los hombres.

\section{REFERENCIAS}

Altuna, B. (2010). Una historia moral del rostro. Valencia: Pretextos.

Álvarez Rodríguez, B. (2011). Sobre la construcción de utopías y contrautopías en la Antigüedad griega a través de "lo Otro". Un acercamiento a la Odisea. Daimon. Revista Internacional de Filosofía, Suplemento 4 "Razón, crisis y utopia”, 233-240.

Bello Reguera, G. (2011). Emigración y Ética. Humanizar y Deshumanizar. Madrid: Plaza y Valdés.

Buxton, R. (2000). El imaginario griego. Los contextos de la mitología. Madrid: Cambridge University Press (Obra original publicada en 1994, Cambridge).

Cabrera Bonet, P. (2003). Cuentos y folclore en Homero: la imagen del Otro. En P. Cabrera Bonet y R. Olmos (Eds.), Sobre la Odisea. Visiones desde el mito y la arqueología (pp. 263-292). Madrid: Ediciones Polifemo.

Cinalli, A. (2015). Ta xenía: la cerimonia di ospitalitá cittadina. Roma: Sapienza Università Editrice.

Courbin, P. (1955). Un fragment de cratère protoargien. Bulletin de Correspondance Hellénique, 79, 1-49.

Gómez Espelosín, F. J. (1994). Tierras fabulosas del imaginario griego. En Tierras fabulosas de la Antigüedad (pp. 103-306). Alcalá de Henares: Universidad de Alcalá. Servicio de Publicaciones.

Gómez Espelosín, F. J. (2004). El descubrimiento del mundo. Geografía y viajeros en la antigua Grecia. Madrid: Akal.

Grimal, P. (2008). Diccionario de mitología griega y romana. Barcelona: Ediciones Paidós (Obra original publicada en 1951 [19796] , París).

Harrauer, C. y Hunger, H. (2008). Diccionario de mitología griega y romana. Barcelona: Herder (Obra original publicada en 2006, Purkersdorf).

Hesíodo. (1978). Teogonía (Trad. A. Pérez Jiménez y A. Martínez Díez). Madrid: Gredos.

Homero. (2010). La Odisea (Trad. J. L. Calvo). Madrid: Cátedra.

Maquieira, H. (1997). Estudio lingüístico y trasfondo cultural de las fórmulas del viaje al Hades en los poemas homéricos. En F. Rodríguez Adrados y A. Martínez Díez (Eds.), Actas del IX Congreso Español de Estudios Clásicos II (pp. 147-151). Madrid: Sociedad Española de Estudios Clásicos y Ediciones Clásicas.

Martínez, J. (1999). Propios, ajenos y extraños. Percepción etnográfica en Homero. Veleia, 16, 221-232.

Mastromarco, G. (1998). La degradazione del mostro. La maschera del Ciclope nella commedia e nel dramma satiresco del quinto secolo a. C. En A. M. Belardinelli (Ed.), Tessere. Frammenti della commedia greca: studi e commenti (pp. 9-42). Bari: Adriatica editrice.

Rodríguez López, M. I. (2010). Iconografía de Polifemo: la tradición homérica y sus pervivencias. Cuadernos de Filología Clásica. Estudios griegos e indoeuropeos, 20, 179-200.

\section{Notas}

* Bárbara Álvarez Rodríguez es Doctora en Filosofía por la Universidad de Oviedo, donde estuvo trabajando durante cuatro años como investigadora predoctoral. Actualmente, está trabajando como Profesora Asociada en la Universidad 
Internacional de La Rioja y forma parte del gabinete de la Consejera de Educación, Universidades, Cultura y Deportes del Gobierno de Canarias. Realizó su investigación posdoctoral durante dos años en el Departamento de Clásicas de la Universidad de Stanford (USA), con el proyecto titulado "Exclusion and Marginalization in the Greek Epic. A study on the relations with the Other in the Iliad". Una parte de este Proyecto la llevó a cabo como Visiting Scholar en el Center for Hellenic Studies de la Universidad de Harvard (USA). Ha participado en congresos y seminarios en USA y España y ha publicado varios artículos en diversos países como España, USA y Portugal, entre los que se encuentran: "Who is counting? Appreciating the peer, despising the Other. An alterity study about social relationships in Homeric Communities" en Cadmo. Revista de Historia Antiga, 26, 2017, 81-116; "Alterity in Homer: a reconceptualization of female marginalization" en Journal of Research in Gender Studies 7(1), marzo 2017, 83-122; "Papel e imagen social de las mujeres en los poemas homéricos desde la perspectiva de su alteridad" en Daimon. Revista Internacional de Filosofía, 70, abril 2017, 7-22.

1 Debo agradecer a los revisores por sus constructivas aportaciones al texto inicial. Igualmente, cualquier fallo que se encuentre en él es mi responsabilidad.

2 Sobre los mecanismos de veridicción, véase Gómez Espelosín (2004).

3 El concepto de alteridad que manejo en todo el artículo es el de alteridad filosófica. E. Levinas fue el primer filósofo que resaltó la importancia de esta categoría como categoría ética y, en última instancia, filosófica, ya que para él la filosofía primera no debía ser la metafísica, como se había sostenido tradicionalmente, sino la ética. A su vez, dentro de esta alteridad filosófica, me referiré, más específicamente, a la alteridad neutra o impersonal. Para más información sobre la tipología de la alteridad que manejo aquí, véase Bello Reguera (2011).

4 Las traducciones de la Ilíada y la Odisea son fruto del trabajo conjunto con la Dra. Lucía Rodríguez-Noriega Guillen y de la consulta continuada de las ediciones de la Ilíada y la Odisea de Gredos (trad. E. Crespo y J. M. Pabón, respectivamente).

5 En las representaciones más antiguas que conservamos de Polifemo, que son varios recipientes de cerámica de la primera mitad del s. VII a. C., el cíclope aparece representado de perfil con el ojo de frente, debido a las convenciones pictóricas de la época. Se trata, en concreto, de un ánfora de Eleusis (ca. 670 a. C.) en la que vemos a un hombre, todo parece indicar que Odiseo, clavándole la estaca a Polifemo, quien sostiene en su mano una copa de vino; la crátera de Aristonoto de Cerveteri (primera mitad del siglo VII a. C.), en la que se ve a cinco hombres intentando clavar la estaca en el ojo del cíclope, que aparece echado en el suelo; y una crátera protoargiva (ca. 650 a. C.), en la que varios personajes aparecen también cegando al cíclope, que tiene ya el ojo saltado y la cara cubierta de sangre.

6 Véase al respecto Courbin (1955), Harrauer y Hunger (2008) s.v. Polifemo, y Rodríguez López (2010, p. 182).

7 Cita extraída de Mastromarco (1998, p. 16); la traducción es mía.

8 Más información sobre el deber de xenía en Cinalli (2015).

9 Es de sobra conocido este episodio, en el que Odiseo, con fines prácticos, se des-identifica convirtiéndose, así, en "Nadie”. El héroe, para salvarse del cíclope, ha de convertirse en "Nadie", negación de su propia persona. Pero este abandono al olvido solo será pasajero, pues, al final, Odiseo reclamará como suya la afrenta contra Polifemo: “iCíclope! Si alguno de los hombres mortales / te pregunta por la odiosa ceguera de tu ojo, / dile que te dejó ciego Odiseo sitiador de ciudades, / el hijo de Laertes, que tiene en Ítaca su casa" (Od. 9.502-505).

10 La traducción es mía. 